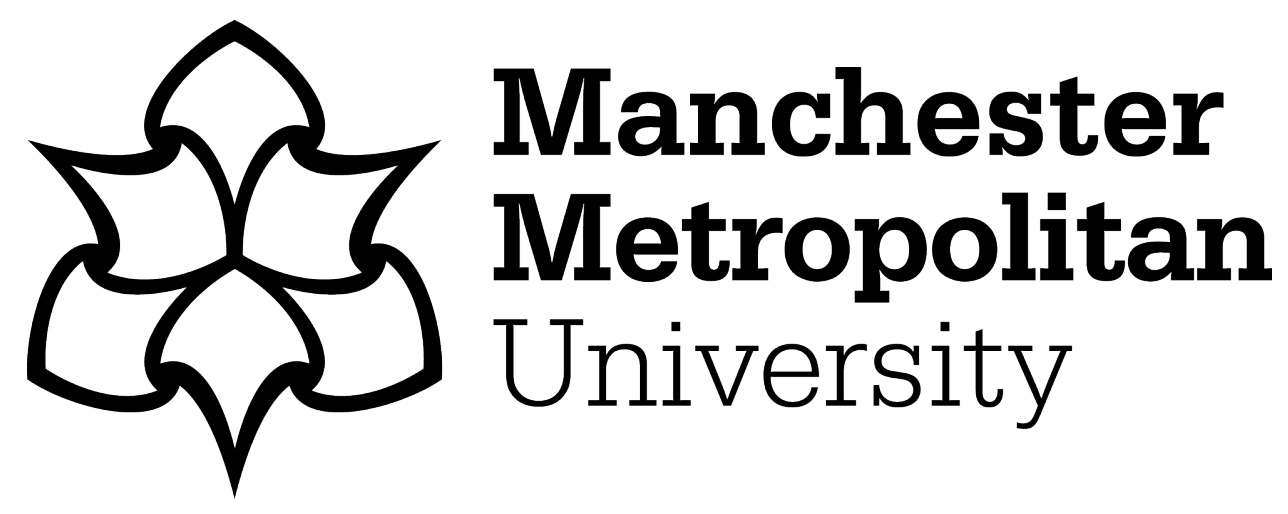

Crowder, Mark, Antoniadou, Marilena and Stewart, Jim (2018) To BlikBook or not to BlikBook: Exploring student engagement of an online discussion platform. Innovations in Education and Teaching International, 56 (3). pp. 295-306. ISSN 1470-3297

Downloaded from: https://e-space.mmu.ac.uk/621455/

Version: Accepted Version

Publisher: Taylor \& Francis (Routledge)

DOI: https://doi.org/10.1080/14703297.2018.1502091

Please cite the published version 


\title{
To BlikBook or not to BlikBook: Exploring student engagement of an online discussion platform
}

\author{
Mark Crowder ${ }^{\mathrm{a}}$, Marilena Antoniadou ${ }^{\mathrm{b}}$ and Jim Stewart ${ }^{\mathrm{c}}$ \\ aDepartment of Strategy, Enterprise and Sustainability, Manchester Metropolitan University Business \\ School, Manchester, UK; ' ${ }^{\text {Department }}$ of People and Performance, Manchester Metropolitan University, \\ Manchester, UK; 'Liverpool Hopes University Business School, Liverpool, UK
}

\begin{abstract}
This paper reports on the use of BlikBook, a course engagement platform for tutors and students that facilitates academic engagement in higher education. Based on a case study where BlikBook was essential to the design and delivery of a large undergraduate module, the paper discusses how the platform opens new avenues for student feedback, and encourages more independence in peer-led student groups. The paper makes several important contributions to knowledge and practice. Firstly, it outlines the process of introducing new software within a university context, and identifies potential pitfalls. Secondly, it off ers an assessment of BlikBook that was previously untried in the case study organisation. Thirdly, previous studies have focused primarily on students' perceptions of online platforms, rather than on the differences in experiences between students and tutors, whereas the present study explores both aspects. Findings suggest that incorporating BlikBook in teaching could improve student engagement.
\end{abstract}

Abbreviation: (HE) - Higher Education
KEYWORDS

BlikBook; course engagement platform; student engagement; higher education

\section{Introduction}

Virtual Learning Environments (VLEs) allow users to share information and add online elements to courses traditionally delivered face-to-face. Their benefits for learning, student engagement and student achievement have been well documented (Stricker, Weibel, \& Wissmath, 2011), although participation may be extremely limited (Deng \& Tavares, 2013), with students engaging in subject discussions on social media more frequently than online platforms (Hou, Wang, Lin, \& Chang, 2015). Thus, there are challenges for tutors. Previous studies of student engagement with online platforms focused primarily on students' perceptions (e.g. Abedin, Daneshgar, \& D'Ambra, 2011), with little attention being given to the differences that students and educators may have.

This study explores the use of one course engagement platform, BlikBook, on one HE module to explore the levels of participation, student discussion and experience, and

CONTACT Marilena Antoniadou m.antoniadou@mmu.ac.uk School, All Saints Building, Manchester, M15 6BH, UK 
the diff erences that tutors and students experienced when using it. The study centres on two key objectives: (i) to identify students' and tutors' perceptions of the use of BlikBook

(ii) to explore students' academic engagement with BlikBook.

\section{Conceptualising student engagement}

Student engagement involves the time and physical energy that students spend on activities in their academic experience, such as to study a subject, obtain feedback and solve problems (Kuh, 2003). Kahu (2013) off ers a model of student engagement, but this highlights factors, which are beyond the scope of this paper, such as political and socio- cultural aspects. However, other frameworks (Harper \& Quaye, 2015; Kuh, 2001) identify a set of specific educational practices that are linked to student engagement, namely academic challenge, learning with peers, student-faculty interaction, and enriching educational experiences. Hence, an important component of student engagement is how institutions deploy their resources, learning opportunities, and support services to induce students to participate to activities that lead to educationally purposeful experi- ences (Kuh, Kinzie, Buckley, Bridges, \& Hayek, 2011). This focus on student engagement creates a responsibility for institutions to maximise good practices and enhance stu- dents' academic engagement (Pascarella, 2001).

Traditionally, educators simply provided information while students listened passively and merely regurgitated facts (Boling, Hough, Krinsky, Saleem, \& Stevens, 2012), but this results in minimal student interaction (Moore, 1989). Whilst tutor-student delivery is important (Hattingh \& De Kock, 2008), other forms of interaction (student-tutor and student-student) also have significant benefits (Rogan \& De Kock, 2005). For instance, student-led interactions focus on what students think is important as well as on what tutors think is important (Wang, Woo, Quek, Yang, \& Liu, 2012), and sessions can take unexpected and interesting directions (Dixson, 2012). Student-studentinteraction is also important for academic engagement since it moderates power relationship issues, because all participants are equal (Kassens-Noor, 2012).

Another important consideration for student engagement is constructive alignment. This occurs when learning outcomes, teaching methods and assessments are tightly linked (Biggs, 1996), and although the approach is rather old, it remains highly relevant (Croy, 2018; McCann, 2017). For instance, building student engagement with the VLE into the assessment process encourages participation and helps to maximise usage of the platform (Wahab \& Mahboub, 2006). Indeed, in an era of technological change, educators are encouraged to adapt their approaches to consider the different needs of students, and complement the traditional telling method with an advising method whereby students are provided with the scaffolding upon which they can build (Webb, 2009).

\section{BlikBook}

BlikBook is a course engagement platform that relies on online discussion forums. It uses analytics to help educators facilitate student interactions and to help in-group problem solving, particularly amongst large numbers of students. Anyone registered on the platform can ask questions, take part in conversations, and receive academic support. 
BlikBook was founded in 2010 (Outsell, 2013) and it is now used at more than one-third of UK HE institutions (Morabito, 2015). However, to date, there was no empirical attempt to evaluate its impact on student engagement.

\section{Using BlikBook in a management module}

International Strategy Development (ISD) is a final-year module within a large UK undergraduate programme. Students on this module lacked empathy with the current VLE, Moodle, and were reluctant to proactively post questions. BlikBook was identified as having the potential to increase student engagement.

Students were informed about BlikBook in their first ISD lecture, and it was explained that the platform works on an opt-in basis. Students could ignore the platform if they wished, or choose to receive regular updates informing them of the latest postings. When students posted questions, tutors provided the answers via BlikBook and, thus, all students using the platform received the same information at the same time. Tutors could also generate discussion topics and post links to news stories, thereby maintaining relevance and currency of the content.

\section{Methodology}

Thestudyadopted a thematicanalysis methodology (Ritchie \& Spencer, 2002). Data collection and analysis took place in three phases: the 'raw data', student experiences, and tutors' experiences. The starting point was to assess if, and how, students used BlikBook. Although BlikBook's analytic function had not been purchased, it was possible to analyse the number and variety of postings, and thus identifykey issues. Coding was used to summarise themes and trends. Students' viewpoints were initially obtained via in-class discussions during tutorials, and these were supplemented by three focus groups. Tutors' viewpoints were primarily identified via informal discussions, and these were supplemented with two semistructured interviews with the current and future module leaders.

\section{Phase 1: the 'raw data'}

The firststep was to transfer the raw content from BlikBook into a form that could be analysed. On a weeklybasis, the authors copied all postings and pasted them into Excel. The mostbasic analysis was a simple count of the number of postings made in a given week and the number of responses provided. However, for other information, such as nature of the topics being posted, it was necessary to analyse the raw data by means of qualitative coding.

Coding was used to break apart the data, compare it to other data, and then organise it into categories so that themes and patterns could be identified (Charmaz, 2006). Coding therefore goes considerably beyond mere categorisation of data (Thomas, 2006). For example, the initial codes 'VRIO help' and 'value chain help' were subsequently merged into a new code, 'internal analysis help'. This code was itself later merged with the codes 'external analysis help' and 'evaluation help' to form the overall category 'subject-specific help'. In this way, information could be obtained about how many questions were asked about which topics, and whether there was any pattern to this (Charmaz, 2006). 


\section{Phase 2: student discussions}

The 'raw data' could only reveal what questions were being asked, not why they were being asked, therefore it was essential to understand the reasoning behind the choice of questions and obtain student feedback on BlikBook. To achieve this, 12 informal discussions were held during regular tutorials over a three-week period, with 90 students being canvassed each week. Recording was not necessary because this study was only interested in broad themes and patterns, and a verbatim transcript of everything that was discussed was not required (Glaser, 1992). Therefore, notes were taken as the conversation progressed and these were typed up more fully later the same day.

The module contained 440 students, making it impractical to interview everyone. Hence, focus groups allowed a range of views to be gathered in a short space of time. Three focus groups were conducted. These allowed students to reflect upon their overall experience, and the sessions provided a useful counterpoint to the data that was gathered during the informal discussions. Students volunteered for the focus groups based on groups that had been formed for a different module. The selection was, therefore, a purposive sample (Jankowicz, 2005). The focus groups consisted of six, four and five students respectively.

\section{Phase 3: tutor discussions}

Capturing the views of the teaching team was essential to obtain a rounded picture. This was done informally because the tutors were in regular contact with the authors throughout the year as part of their 'day job', and routinely shared opinions and thoughts on many matters, including BlikBook. The data gathered covered day-to-day issues experienced by the tutors. This was supplemented by a more formal discussion at the end of the academic year as part of a scheduled annual debrief of ISD. BlikBook was an agenda item for this meeting, and the authors took notes with the agreement of those concerned. Finally, semi-structured interviews were held with the module leader and with the tutor who was scheduled to take over the module in the coming year. The module leaders provided a strategic view, which complemented the operational data gathered throughout the year.

\section{Ethical considerations}

There was a danger that an informal approach might distort research findings by introducing researcher bias (Tissington \& Orthodoxou, 2014). It was also possible that power relationships might adversely affect the research because students may have perceived the authors as being in a position of power (due to their roles as tutors), and may have tailored their comments accordingly (Easterby-Smith, Thorpe, \& Lowe, 2002). These risks were minimised by ensuring that participants stayed in control as far as possible through- out the process. It was not practical to email draft notes to all participants for their approval to ensure that what the authors thought respondents meant was actually what they did mean (Ang, 2014) because summaries of group discussions might not reflect the views of individual participants. Therefore, each focus group session concluded with the authors summarising the discussion and asking students if their understanding was correct. On two occasions, students requested that some minor changes should be made, and the authors were happy to comply. Before the first focus group session, all 
students had signed a consent form, and prior to each discussion, participants were explicitly assured of their anonymity. They were also reminded that they had an absolute right to withdraw their consent at any stage of the research.

\section{Results}

\section{Student/tutor interaction}

The first theme was 'how often was BlikBook used?', and this was identified by counting the number of posts made each week (Figure 1). A total of 99 posts were made by 72 different students (16\% of the student cohort). Given that there were 440 students, these figures were felt to be relatively low, raising early concerns about BlikBook's use. For four weeks, there were no postings, although there was a significant increase in activity in week 15, and a large jump in week 17 (assessment week). Most of these posts $(92 \%)$ took the form of student questions. Tutors posted seven times - partly to seed discus- sions and partly to notify students of important news.

Having established that the platform was being used, the next question was 'what was it being used for?' This was addressed using coding, as described above, and the following results were obtained (Figure 2):

The greatest number of postings $(51 \%)$ related to subject-specific help. This concerned issues such as difficulty in understanding theory, and how to apply theory to real-life examples. Assignment procedures were also a common theme $(24 \%)$ and featured questions on hand-in dates, use of Turnitln, and word count limits. Exam procedures were of least interest $(1 \%)$, because the exam was three months away at the time

Having identified which subjects were posted most often, the authors wished to determine which topics received the most 'hits', as this would indicate which topics were of most importance to students. The number of views of each question were tallied, and then equated with the coded information relating to postings.

The total number of views was 8922 (Figure 3). This number relates to 409 different students ( $93 \%$ of the student cohort), which broadly equates to 22 hits per student. By far the topic of greatest concern was subject-specific help, which received 8012 views

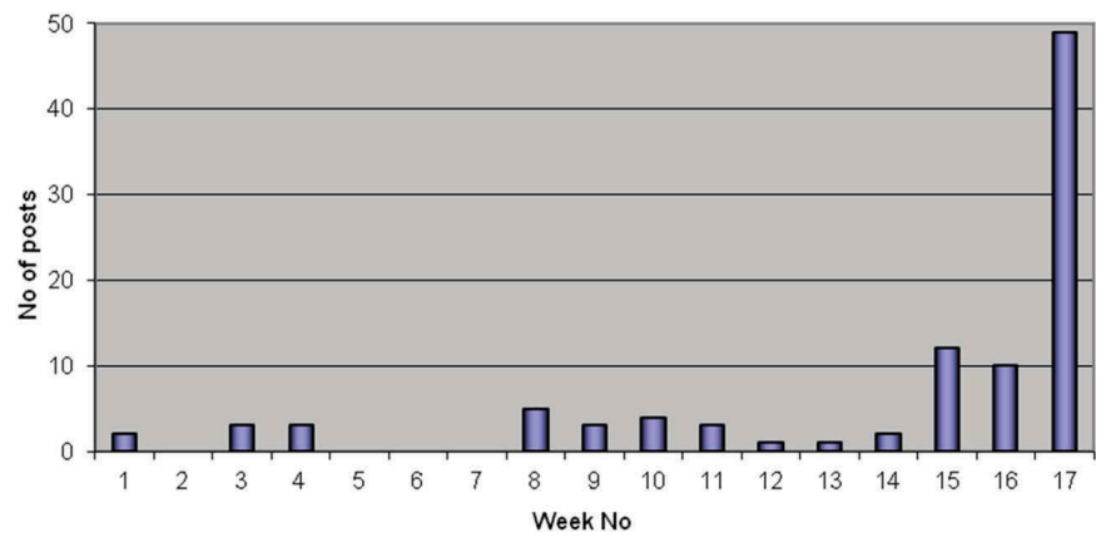

Figure 1. Number of postings in BlikBook per week. 


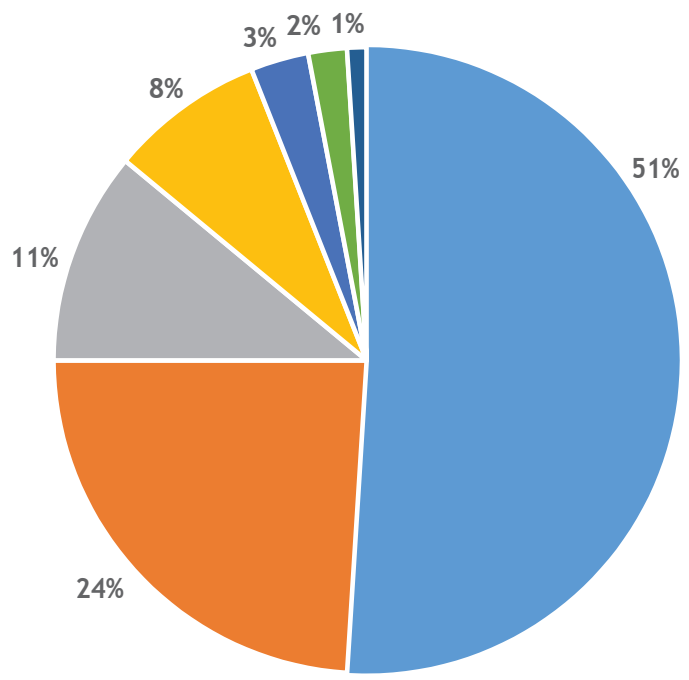

- Subject-specific help

Assignment procedure

Assignment writing

Moodle

General

- Relevant news articles

- Exam procedure

Figure 2. Topics discussed in BlikBook.

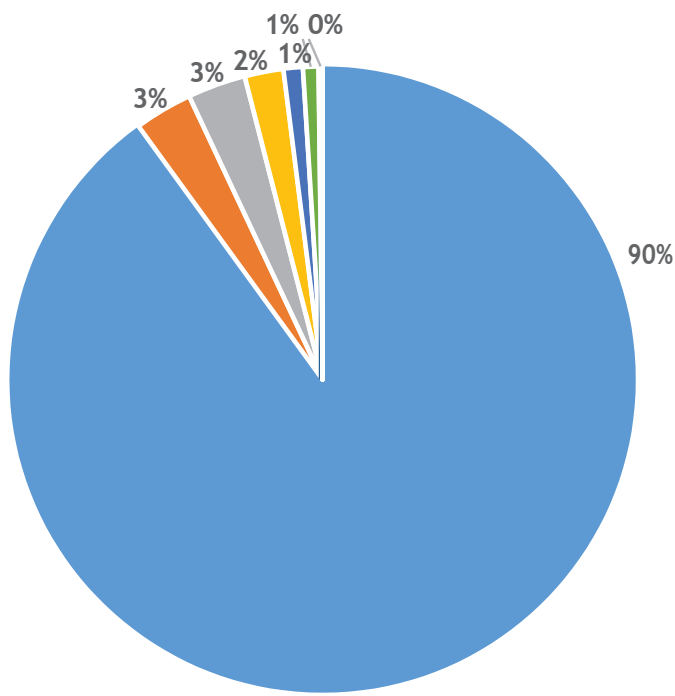

- Subject-specific help

Assignment procedure

- Relevant newsarticles

Assignment writing

Moodle

General

- Exam procedure

Figure 3. Total number of views of topics in BlikBook.

(90\%). Assignment procedure and relevant news articles were the only other topics where substantial interest was shown by students (3\% of views in both cases). Again, exam procedure was of least interest $(0.1 \%)$ because students were focusing almost exclusively on the assignment. The number of posting versus number of views is worthy of note because it emphasises the passive nature of many of the students in this process. 


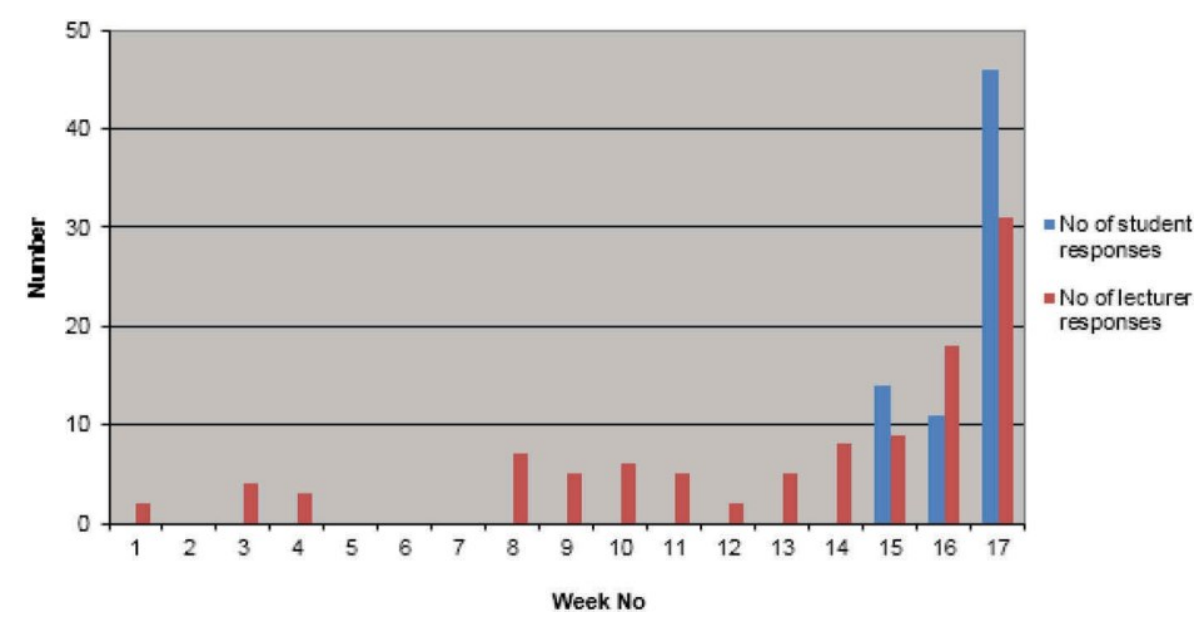

Figure 4. Number of responses to posts per week.

\section{Student/student interaction}

The next area of interest was the extent to which students replied to other students, rather than posts simply being responded to by tutors (Figure 4). The total number of comments was 176 . Of these, 105 were made by tutors $(60 \%)$ and 71 were made by students $(40 \%)$. The 71 student responses were made by 53 diff erent students. Fortytwo students made only a single comment and 11 students were responsible for the remaining 29 comments. There were no student responses before week 15 , but as the number of questions being posted increased, student involvement also increased in terms of replying to other questions. Indeed, the number of student responses exceeded the number of tutor responses in weeks 15 and 17. Although it would have been useful to compare these findings to the pattern of student views over the same period, the figure for 'hits' within BlikBook is cumulative, and cannot be analysed in this way without purchasing the analytics function.

\section{Students' perceptions of BlikBook}

Focus groups revealed that students enjoyed working with BlikBook. They liked its simplicity and its 'intuitive and easy to use' nature.

'With Moodle, group discussions tend to be dry and more like an information dump. It's mostly one-way. BlikBook is better. It's more interactive and feels like you're using social media. Lecturers feel more like friends, but with Moodle, they are more distant' (focus group 2).

The students identified that when being absent from class was unavoidable, BlikBook helped them to stay engaged with the module content:

'I missed a few tutorials because I was working, and BlikBook was a life saver. It let me catch up on what l'd missed. It was really specific and it was just what I needed' (focus group 1)

'l'd been sick for a few weeks, and the lecture notes made no sense in isolation. I posted questions that were bothering me, and I got quick answers back. I got a conversation going with my 
lecturers and that really helped me. I could see from other students' comments that I wasn't the only one who was confused, and so my questions helped other students too' (focus group 2)

The question-and-answer facility was perceived to be a significant strength:

'It saves us [bothering] our lecturers all the time. We can post a question and it will be answered within 24 hours' (student discussion 3).

'Whenever I think of a question, someone has already asked it on BlikBook, and so I get my answers before l've even asked the question!' (focus group 1).

One student favourably compared BlikBook with e-mail:

'I've posted a couple of questions... .and compared to emailing certain tutors, BlikBook is the fastest way to get an answer' (student discussion 9).

This point was supported in several focus groups. For instance, students complained that Tutor 5 was 'distant and hard to contact' (focus group 1), and 'he's never there... you can never get hold of him' (focus group 2). With BlikBook, students felt they got 'better communication' (focus group 2), 'clear answers' (focus group 3), and 'faster replies, which is important when you're stressing over something' (focus group 1). As one student put it, 'this new way [i.e. BlikBook] is just better' (student discussion 2).

Some students felt that student engagement with BlikBook could be improved 'if it became part of the overall assignment grade' (student discussion 1). Essentially, 'if using it was part of the mark, then students would be forced to use it more' (student discussion 2). However, this issue was not raised by other students, who felt that 'BlikBook is fine as it is' (focus group 3).

\section{Tutors' perceptions of BlikBook}

The positive student view of BlikBook was not entirely reflected in tutors' comments. Although tutors recognised BlikBook's strengths, such as being able to proactively post topics and deliver consistent feedback, they believed that it had made students 'lazy':

'Students couldn't be bothered looking properly. They were too lazy to scroll down a page or two, and they kept asking questions we'd already answered. They'd ask the same thing again and again' (tutor 1)

Tutors were unconvinced about the use of BlikBook forming part of the overall assessment. Tutor 3 echoed the views of all tutors:

"It's a slippery slope. How do you measure 'use'? Is posting a comment 'use'? Is viewing a topic 'use'? If a student doesn't need our help and gets $85 \%$ in the assignment without BlikBook, then is it right to penalise them for not using something that doesn't serve a purpose for them?"

Despite the success of BlikBook from a student perspective, its use was terminated earlier than planned. Technical issues, such as BlikBook not working on all internet browsers and, especially, its impact upon tutors' workload were significant challenges. The following comments were typical:

'Students love BlikBook, but it was supposed to cut down on the number of emails. But, emails are worse than ever, and we're answering on BlikBook too! I've got less time now not 
more time. Plus, you need to have the latest version of Chrome and Internet Explorer, but we didn't, and we had to get IT to sort it out for us.' (tutor 2)

'Students posted questions on Friday night after we'd gone home for the weekend, but were still expecting an answer. So, I ended up practically using the platform 24/7.' (tutor 4)

Workload issues meant that tutors were keen to dispense with the platform at the first opportunity. However, even though tutors disliked aspects of the platform, they did concede that there are some areas that were helpful. Most importantly, BlikBook helped them achieve transparency in their guidance and feedback, and for the first time, they had no complaints about inconsistency - something that was prevalent in the past with the use of emails.

\section{Discussion}

The study explored student participation and engagement and identified strengths and pitfalls of using BlikBook. The findings reflect existing theoretical frameworks of student engagement (e.g. Kuh, 2001), especially in respect of learning with peers and studentfaculty interaction. This gives a strong basis for further monitoring of the progress of this innovative platform, which helps in taking the tool forward.

BlikBook usage was broadly consistent up to Week 15, when there was a significant rise, which then exponentially increased in Week 17 . This was directly attributable to the fact that the assignment was submitted in Week 17. Such findings are perhaps unsurprising, and reflect previous research which indicates that students only really begin to use their VLE fully when it becomes particularly relevant to them (McGill \& Hobbs, 2007).

The number of student hits on a particular part of a VLE can be viewed as a measure of its success (Lyndon \& Hale, 2014), although this is but one indicator and others, such as student perception, are at least as important (Stricker et al., 2011). Nevertheless, 99 postings were made by 72 different students (16\% of the cohort), and almost 9000 views were made in a 17-week period by over 400 different students ( $93 \%$ of the cohort). These figures contrast markedly with previous research into classroom-based engagement, which indicates that most engagement comes from a small number of students (see for instance Fritschner, 2000). Hence, by this metric, BlikBook has been a success.

Subject-specific support was, by a large margin, the most discussed topic, which confirms the importance of specific and detailed feedback (Stiggins, Chappuis, \& Arter, 2014). Consistency of feedback was repeatedly stressed by all parties as crucial (Ferguson, 2011). However, although tutors accepted the benefits of BlikBook, they were critical of student usage, felt that it made students lazy, and argued that it created more work for themselves.

There was also evidence of student/student interaction. In an era when formalised collaborative learning can be difficult to achieve (Hou et al., 2015), when students got involved from week 15 onwards, after becoming more familiarised with BlikBook, they did so very energetically. Peer-to-peer learning has been shown to be very beneficial as it allows students to use their own knowledge and experience for the benefit of others, and gain insights from colleagues in return (Hilsdon, 2014). 


\section{Limitations and future research}

This study showed that BlikBook was important to the design and delivery of the curriculum in a large final year module; however, it did not specifically explore the relationship between students' academic performance and use of BlikBook. This study also concentrated on one module in a single $\mathrm{HE}$ institution. Thus, future research could study other contexts and explore the extent to which BlikBook, and other course engagement platforms, can improve student performance. Finally, this study did not probe the potential effects of individual student/tutor diff erences, such as gender, age or prior experience, and these are other avenues for future research.

\section{Taking BlikBook forward}

Online discussion forums are common, and are popular with students (Stricker et al., 2011). BlikBook gave tutors new and innovative avenues for student feedback, and resulted in more independence in peer-led studentgroups. Students liked the platformand used itextensively, especiallyin the weeks approaching assignmentsubmission. Theyfound iteasyto use, and it was particularly popular when students were seeking technical advice on their assessment, and student-student interaction was very strong during this period. To this extent, BlikBook was successful. However, tutors felt that the strengths of the tool were outweighed by significantly increased workloads, although they acknowledged this could be due to how BlikBook was managed, rather than problems with the platform itself. These objections were so great that tutors stated they were unwilling to use it again. However, BlikBook has the potential to contribute to student engagement if it is moderated. Moderated forums are common whereitis desirable to keepcomments civilandensurethat theystayontopic(Jones \& Ryan, 2014), and in these instances an editor will control postings that breach the site's guidelines. The fact that students repeatedly asked the same question was a concern, and perhaps moderators might identify these issues before they reach tutors. Discussion forums can alsobe used to address areas thatare not covered in detail on the 'main' course. Although this was notan issue in the present study, this idea could be considered if BlikBook was used again. Potentially, BlikBook could fruitfully be used as part of the assessment process. This was suggested by some students in this study, and may improve engagement with the platform (Wahab \& Mahboub, 2006). However, tutors were unanimously against this, not because of opposition to the platform, but because of perceived issues with practicality and fairness.

\section{Disclosure statement}

No potential conflict of interest was reported by the authors.

\section{Notes on contributors}

Mark Crowder is Senior Lecturer at Manchester Metropolitan University. He studied at LJMU and the University of Liverpool before gaining his $\mathrm{PhD}$ in cognitive psychology at the University of Chester. His research interests focus upon decision-making and HigherEducation. 
Marilena Antoniadou is Senior Lecturer at Manchester Metropolitan University. Her PhD in Organisational Behaviour specialises in the role of discrete emotions and emotional events in the workplace. Her research interests are also within the field of Higher Education.

Jim Stewart is Professor in HRD at Liverpool John Moores University. He is author/co-author/coeditor of 25 books on the topics of HRD and Learning and Development as well as numerous journal articles. Jim is a former Vice Chair for Research and Chair of UFHRD. He is currently UFHRD Executive Secretary.

\section{References}

Abedin, B., Daneshgar, F., \& D'Ambra, J. (2011). Enhancing non-task sociability of asynchronous CSCL environments. Computers \& Education, 57, 2535-2547.

Ang, S. H. (2014). Research design for business and management. London: Sage.

Biggs, J. (1996). Enhancing teaching through constructive alignment. Higher Education, 32, 347-364.

Boling, E. C., Hough, M., Krinsky, H., Saleem, H., \& Stevens, M. (2012). Cutting the distance in distance education: Perspectives on what promotes positive, online learning experiences. The Internet and Higher Education, 15, 118-126.

Charmaz, K. (2006). Constructing grounded theory. London: Sage.

Croy, S. R. (2018). Development of a group work assessment pedagogy using constructive alignment theory. Nurse Education Today, 61, 49-53.

Deng, L., \& Tavares, N. J. (2013). From Moodle to Facebook: Exploring students' motivation and experiences in online communities. Computers \& Education, 68, 167-176.

Dixson, M. D. (2012). Creating eff ective student engagement in online courses: What do students find engaging? Journal of the Scholarship of Teaching and Learning, 10, 1-13.

Easterby-Smith, M., Thorpe, R., \& Lowe, A. (2002). Management research: An introduction (2nd ed.). London: Sage.

Ferguson, P. (2011). Student perceptions of quality feedback in teacher education. Assessment \& Evaluation in Higher Education, 36, 51-62.

Fritschner, L. M. (2000). Inside the undergraduate college classroom: Faculty and students diff er on the meaning of student participation. Journal of Higher Education, 71, 342-362.

Glaser, B. G. (1992). Basics of grounded theory analysis: Emergence vs forcing. Mill Valley, CA: Sociology Press.

Harper, S. R., \& Quaye, S. J. (2015). Making engagement equitable for students in U.S. higher education. In S. J. Quaye \& S. R. Harper (Eds.), Student engagement in higher education: Theoretical perspectives and practical approaches for diverse populations (Second ed., pp. 1-14). New York, NY: Routledge.

Hattingh, A., \& De Kock, D. M. (2008). Perceptions of teacher roles in an experience-rich teacher education programme. Innovations in Education and Teaching International, 45, 321-332.

Hilsdon, J. (2014). Peer learning for change in higher education. Innovations in Education and Teaching International, 51, 244-254.

Hou, H. T., Wang, S. M., Lin, P. C., \& Chang, K. E. (2015). Exploring the learner's knowledge construction and cognitive patterns of different asynchronous platforms: Comparison of an online discussion forum and Facebook. Innovations in Education and Teaching International, 52, 610-620.

Jankowicz, A. D. (2005). Business Research Projects (4th edn). London: Thomson Learning.

Jones, M., \& Ryan, J. (2014). Learning in the practicum: Engaging pre-service teachers in reflective practice in the online space. Asia-Pacific Journal of Teacher Education, 42, 132-146.

Kahu, E. R. (2013). Framing student engagement in higher education. Studies in Higher Education, $38,758-773$.

Kassens-Noor, E. (2012). Twitter as a teaching practice to enhance active and informal learning in higher education: The case of sustainable tweets. Active Learning in Higher Education, 13, 9-21.

Kuh, G. D. (2001). Assessing what really matters to student learning inside the national survey of student engagement. Change: the Magazine of Higher Learning, 33,10-17. 
Kuh, G. D. (2003). What We're learning about student engagement from NSSE: Benchmarks for eff ective educational practices. Change: the Magazine of Higher Learning, 35(2), 24-32.

Kuh, G. D., Kinzie, J., Buckley, J. A., Bridges, B. K., \& Hayek, J. C. (2011). Piecing together the student success puzzle: Research, propositions, and recommendations: ASHE Higher Education Report (116). San Francisco, CA: John Wiley \& Sons.

Lyndon, S., \& Hale, B. (2014). Evaluation of how the blended use of a virtual learning environment (VLE) can impact on learning and teaching in a specific module. Enhancing Learning in the Social Sciences, 6, 56-65.

McCann, M. (2017). Constructive alignment in economics teaching: A reflection on eff ective implementation. Teaching in Higher Education, 22, 336-348.

McGill, T. J., \& Hobbs, V. J. (2007). How students and instructors using a virtual learning environment perceive the fit between technology and task. Journal of Computer Assisted Learning, 24, 191-202.

Moore,M. G. (1989). Editorial:Threetypes ofinteraction. American JournalofDistance Education, 3,1-7.

Morabito, V. (2015). Big Data and Analytics: Strategic and Organizational Impacts. London: Springer International.

Outsell (2013). Blikbooks: Addressing the UK market for higher Ed E-textbooks [online]. Retrieved from https://web.archive.org/web/20131213053912/http://outsellinc.net/Headline.aspx?ID=455070

Pascarella, E. T. (2001). Identifying excellence in undergraduate education are we even close? Change: the Magazine of Higher Learning, 33, 18-23.

Ritchie, J., \& Spencer, L. (2002). Qualitative data analysis for applied policy research. In M. Huberman \& M. B. Miles (Eds), The qualitative researcher's companion (pp. 305-329). Thousand Oaks, CA: Sage.

Rogan, A. I., \& De Kock, D. M. (2005). Chronicles from the classroom: Making sense of the methodology and methods of narrative analysis. Qualitative Inquiry, 11, 628-649.

Stiggins, R., Chappuis, S., \& Arter, J. (2014). Classroom assessment for student learning. Harlow: Pearson.

Stricker, D., Weibel, D., \& Wissmath, B. (2011). Efficient learning using a virtual learning environment in a university class. Computers \& Education, 56, 495-504.

Thomas, D. R. (2006). A general inductive approach for analyzing qualitative evaluation data. American Journal of Evaluation, 27, 237-246.

Tissington, P., \& Orthodoxou, C. (2014). Study skills for business and management: How to succeed at university and beyond. London: Sage.

Wahab, M. M. A., \& Mahboub, D. (2006). Students understanding and participation using ULearn: Dynamics case. European Journal of Engineering Education, 31, 407-420.

Wang, Q., Woo, H. L., Quek, C. L., Yang, Y., \& Liu, M. (2012). Using the Facebook group as a learning management system: An exploratory study. British Journal of Educational Technology, 43, 428-438.

Webb, N. M. (2009). The teacher's role in promoting collaborative dialogue in the classroom. British Journal of Educational Psychology, 79, 1-28. 